\title{
ANALISIS CACAT PRODUK GREEN TYRE DENGAN PENDEKATAN SEVEN TOOLS
}

\author{
Joko Hardono, Hendra Pratama, Andi Friyatna \\ Program Studi Teknik Industri, Fakultas Teknik, Universitas Muhammadiyah Tangerang \\ Email:jhardono@yahoo.com; hendra.pratama@umt.ac.id; andi.friyatna23@gmail.com
}

\begin{abstract}
Abstrak - Kualitas merupakan salah satu aspek yang perlu dijaga dalam meningkatkan kepercayaan konsumen dan meminimalkan biaya produksi. Sebuah perusahaan pembuatan ban motor mengalami kecacatan produksi sebanyak 5028 buah selama bulan februari 2018. Penelitian ini bertujuan menurunkan jumlah produk cacat pada proses pemasakan green tyre di area curing. Metode yang dipakai dalam penelitian ini adalah seven tools khususnya diagram pareto dan diagram fishbone serta dianalisis penyebabnya dengan $5 \mathrm{~W} 1 \mathrm{H}$. Dari enam jenis cacat green tyre, under cure merupakan faktor yang paling dominan (40\%) yang menyebabkan terjadinya cacat. Perbaikan Pneumatic Problem yang merupakan problem terjadinya under cure dari faktor manusia, mesin dan metode mampu menurunkan cacat sebesar 48\% dari 891 pieces di bulan Februari menjadi 463 pieces di bulan Mei. Penurunan cacat pada pneumatic problem berefek pada penurunan jumlah cacat produk green tyre dari 5206 pieces di bulan Februari menjadi 4699 pieces di bulan Mei.
\end{abstract}

Kata kunci: Cacat, Diagram Fishbone, Green Tyre, 5W1H

\begin{abstract}
Quality is one aspect that needs to be maintained in increasing consumer confidence and minimizing production costs. A motorcycle tire manufacturing company has a production defect of 5028 during February 2018. This study aims to reduce the number of defective products in the green tire cooking process in the curing area. The methods used in this study are seven tools, especially Pareto diagrams, and fishbone diagrams and analyzed the cause is $5 \mathrm{~W} 1 \mathrm{H}$. Of the six types of green tire defects, under cure is the most dominant factor (40\%) that causes disability. The improvement in Pneumatic Problems which the problem of under cure is human factors, machinery, and the method of being able to reduce defects by $48 \%$ from 891 pieces in February to 463 pieces in May. The decrease in defects in pneumatic problems affects the reduction in the number of defects in green tire products from 5206 pieces in February to 4699 pieces in May.
\end{abstract}

Keywords: Defect, Fishbone Diagram, Green Tyre, 5W1H

\section{PENDAHULUAN}

Kualitas merupakan salah satu aspek faktor dalam memenangkan persaingan pasar yang semakin kompetitif. Kualitas yang baik adalah produk sesuai dengan standar yang telah ditetapkan sebelumnya. Produk yang berkualitas secara tidak langsung akan meningkatkan kepercayaan konsumen sehingga mampu meningkatkan loyalitas konsumen (Chandradevi \& Puspitasari, 2016)

Produk yang berkualitas secara tidak langsung akan berdampak pada produktivitas perusahaan dan meminimalkan biaya produksi. Perusahaan perlu melakukan analisis dan perbaikan secara terus menerus untuk menjaga produk yang dihasilkan sesuai dengan spesifikasi yang telah ditetapkan (Matondang \& Ulkhaq,
2018). Langkah yang dapat dilakukan dalam menjaga produk yang sesuai dengan standar yang telah ditetapkan adalah dengan menerapkan pengendalian kualitas. Pengendalian kualitas merupakan proses pengawasan mutu dalam rangka mempertahankan kualitas produk yang dihasilkan (Bakhtiar, Tahir, \& Hasni, 2013).

Sebuah perusahaan yang bergerak dalam bidang pembuatan ban motor juga mengalami permasalahan dengan kualitas produk yang dihasilkan. Dalam proses produksi di area curing masih sering terjadi produk yang cacat sehingga menurunkan kualitas produksi. Selama bulan Februari 2018 produk yang mengalami kecacatan sebanyak 5028 pieces. Jika ini tidak ditangani secara serius akan berdampak pada 
peningkatan biaya produksi dan secara tidak langsung akan mengurangi kepercayaan konsumen jika produk tersebut sampai diterima oleh konsumen.

Penelitian ini dimaksudkan untuk menurunkan jumlah produk cacat pada proses pemasakan green tyre di area curing. Penelitian dilakukan dengan cara mengidentifikasi jenis cacat dalam pemasakan green tyre, menentukan cacat dominan kemudian melakukan tindakan menurunkan cacat dominan tersebut.

\section{METODE PENELITIAN}

Penelitian ini dilakukan di perusahaan ban motor di daerah tangerang berdasarkan data cacat produksi selama bulan Februari 2018. Analisis data menggunakan metode seven tools untuk mencari penyebab cacat yang terjadi.

Seven tools adalah tujuh macam alat yang digunakan untuk mengidentifikasi dan menganalisa permasalahan yang berkaitan dengan kualitas dalam produksi (Girish, 2013). Ketujuh alat tersebut antara lain: Lembar Periksa (Check Sheet), Histogram, Pareto Diagram, Fishbone Diagram, Scatter Diagram, Flowchart,dan Control Chart. Dalam penelitian ini tools yang digunakan adalah Pareto Diagram dan Fishbone Diagram. Hasil Fishbone Diagram dianalisis menggunakan $5 \mathrm{~W}+1 \mathrm{H}$ untuk mendapatkan informasi yang lengkap terhadap objek yang akan dianalisa sebagai dasar menentukan tindakan perbaikan yang diperlukan.

Pareto Diagram merupakan alat bantu peningkatan kualitas dalam menentukan tingkat cacat yang terjadi dari beberapa masalah yang terjadi (Safrudin \& Sari, 2016). Pareto diagram dapat menghasilkan cara untuk mengidentifikasi mengenai peningkatan kualitas, dan meningkatkan efisiensi, sisa material maupun pengurangan biaya (Neyestani, 2017).

Fishbone diagram merupakan alat penting yang digunakan untuk mencari tahu akar penyebab masalah. Dalam teknik ini semua kemungkinan penyebab masalah diperhitungkan dan mencoba mencari tahu alasan setiap penyebab yang membuat masalah terjadi (Muhammad, 2015; Tague, 2005).

Pada dasarnya $5 \mathrm{~W} 1 \mathrm{H}$ adalah suatu metode yang digunakan untuk melakukan investigasi terhadap masalah yang terjadi dengan menggunakan pertanyaan What, Where, Why, Who, When dan How. Dari hasil investigasi ini diperoleh hasil yang dapat digunakan untuk menyelesaikan permasalahan yang terjadi.

\section{HASIL DAN PEMBAHASAN}

Curing tyre adalah tahap terakhir dari proses pembuatan ban, green tyre yang dihasilkan dari proses perakitan kemudian dikirim ke area curing untuk dimasak. Proses curing adalah pemasakan atau vulkanisasi dengan suhu dan tekanan tinggi untuk menyatukan polymer (rubber) dengan carbon black dan sulphur dengan dibantu oleh persenyawaan kimia untuk mendapat karakteristik compound yang diperlukan dari bagian-bagian ban. Sehingga menjadi suatu produk ban yang berkualitas.

Pada proses pemasakan Green Tyre masih terjadi defect atau cacat produk yang dapat menurunkan kualitas produk. Untuk menangani hal ini pertama harus diketahui jenis cacat apa yang terjadi pada proses pemasakan Green Tyre. Lalu mencari cacat paling dominan dan cara atau tindakan untuk mengatasi cacat dominan tersebut.

Dari hasil wawancara dan data yang diperoleh perusahaan didapatkan enam jenis cacat yang terjadi pada proses pemasakan Green Tyre. Keenam jenis cacat tersebut adalah:

\section{Open Mold}

Cacat ini terjadi dimana pada proses pemasakan cetakan (mold) tidak tertutup rapat sehingga ada bagian bahan dari Green Tyre yg keluar dari cetakan (Gambar 1).

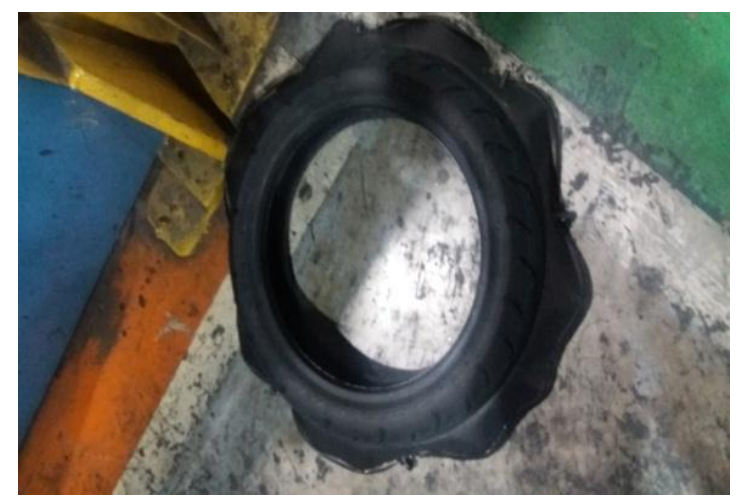

Gambar 1 Open Mold

\section{Blond Tread}

Apabila kondisi Green Tyre pada bagian tread masih terdapat angin yang mengendap lalu dilakukan pemasakan maka hasil pada proses ini akan terdapat gelembung udara pada produk dikarenakan udara yang mengendap tadi.

\section{Inner Pass}

Kondisi bladder yang kurang di perhatikan juga bisa menyebabkan terjadinya cacat produk. Dari bladder yang bocor akan mengeluarkan steam di dalamnya ketika proses pemasakan. Steam yang langsung mengenai Green Tyre tentunya dapat merusak tekstur bahan tersebut. 
4. Bead Crack

Cacat ini terjadi pada sisi Green Tyre yaitu pada bagian kawat (bead) yang kurang rapat saat proses penyatuan sehingga terjadi crack saat Green Tyre dilakukan proses pemasakan.

\section{Nero Bead}

Ketika cetakan (mold) terdapat cacat pada bagian samping tentunya akan menyebabkan bead atau kawat akan menjadi rusak.

6. Under Cure

Cacat ini terjadi dari beberapa faktor penyebab pada proses pemasakan Green Tyre. Faktor-faktor tersebut meliputi kondisi Bladder, Topring bocor, Overload, Oil pump drop, dan Pneumatic (Gambar 2).

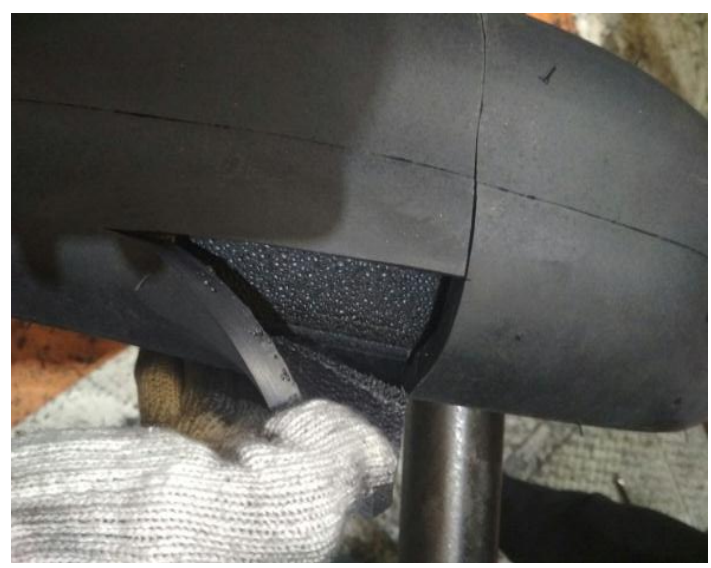

Gambar 2. Under Cure

Data produk green tyre selama bulan Februari 2018 adalah sebesar 330.060 pieces dan jumlah cacat produk sebesar 5250 pieces. Dari jumlah produk cacat dilakukan stratifikasi berdasarkan jenis cacat seperti pada tabel 1 .

Tabel 1. Jenis cacat green tyre bulan Februari 2018

\begin{tabular}{llcc}
\hline No & Jenis Cacat & Jumlah Cacat & $\%$ \\
\hline 1 & Open Mold & 791 & $15 \%$ \\
2 & Bead Crack & 407 & $8 \%$ \\
3 & Inner Pass & 779 & $15 \%$ \\
4 & Blond Tread & 828 & $16 \%$ \\
5 & Nero Bead & 357 & $7 \%$ \\
6 & Under Cure & 2088 & $40 \%$ \\
\hline \multicolumn{3}{l}{ Jumlah } \\
\hline
\end{tabular}

Dari data Tabel 1. diketahui bahwa under cure adalah cacat yang paling sering terjadi pada proses pemasakan Green Tyre (cacat dominan) yang nilainya mencapai $40 \%$ dari total cacat. Ada beberapa faktor penyebab terjadinya Under Cure antara lain: Topring problem, Pneumatic problem, Bladder problem, Overload, Oil Pump drop. Dari faktor-faktor tersebut dibuatkan data tabel untuk mengetahui penyebab utama terjadinya Under Cure.

Tabel 2. Klasifikasi Penyebab Under Cure

\begin{tabular}{clc}
\hline No & \multicolumn{1}{c}{ Penyebab } & Jumlah Cacat \\
\hline 1 & Pneumatic Problem & 891 \\
2 & Bladder Problem & 313 \\
3 & Topring Problem & 550 \\
4 & Overload & 167 \\
5 & Oil Pump Drop & 167 \\
\hline & Jumlah & 2088 \\
\hline
\end{tabular}

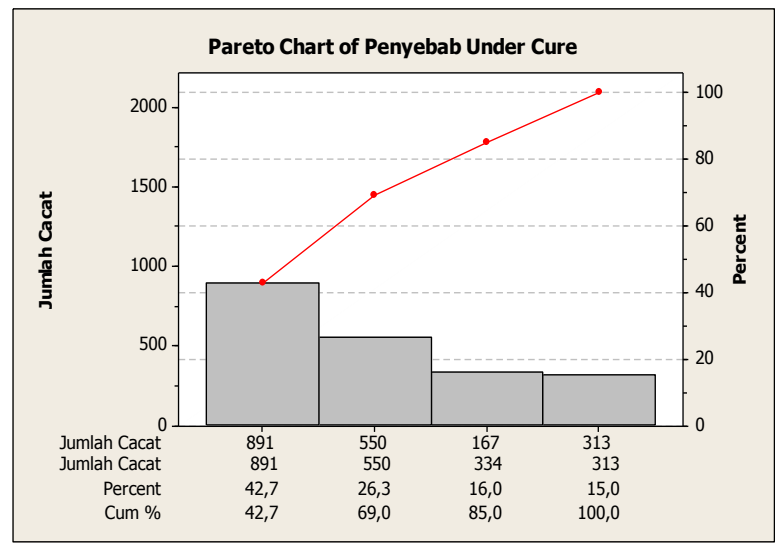

Gambar 3. Diagram Pareto Penyebab Under Cure

Berdasarkan gambar 3 diketahui bahwa Pneumatic Problem adalah masalah utama yang paling sering menyebabkan Under cure yang nilainya mencapai 891 dari total cacat 2088 atau $43 \%$ dari total cacat Under cure. Pembahasan dibatasi pada penyebab dominan yaitu pneumatic problem.

Pneumatic terdiri dari Solenoid dan Piston Valve. Pneumatik sangat berperan penting pada proses pemasakan green tyre dimana Solenoid dan Piston Valve berfungsi untuk memberikan panas steam saat proses pemasakan. Namun pada kondisi lapangan sering terjadi kemacetan yang dialami Solenoid dan Piston Valve yang diakibatkan dari kurangnya supply oli lubrication pada pneumatik ini. 


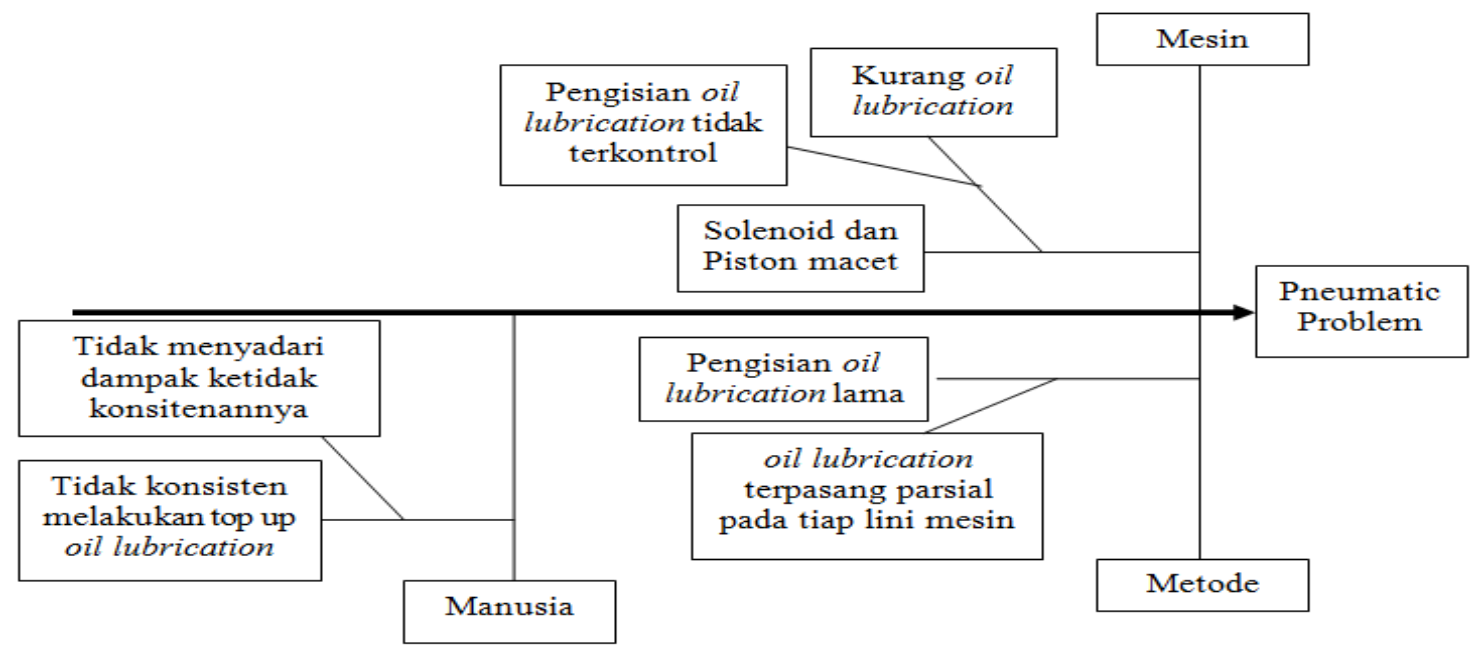

Gambar 4. Fishbone diagram

Ada beberapa faktor yang menyebabkan problem pada pneumatik (Gambar 4), antara lain: 1. Man

Tidak konsisten dalam melakukan top up oil lubrication.

\section{Method}

Dengan banyaknya lini mesin curing maka akan memerlukan waktu yang lama dalam melakukan top up oil lubrication.

\section{Machine}

Solenoid dan piston macet.

Dari faktor penyebab terjadinya pneumatik problem diatas kemudian diidentifikasi akar penyebabnya dengan menggunakan tool diagram tulang ikan. Setelah akar penyebab sudah teridentifikasi langkah selanjutnya adalah melakukan proses perbaikan dengan menggunakan tool 5W1H (Tabel 3) .

Tabel 3. 5W1H Realisasi Penanggulangan

\begin{tabular}{|c|c|c|c|c|c|c|c|}
\hline No & Problem & What & How & Where & Who & When & Why \\
\hline 1 & Mesin & $\begin{array}{l}\text { Pengisian oil } \\
\text { lubrication } \\
\text { tidak } \\
\text { terkontrol. }\end{array}$ & $\begin{array}{l}\text { Membuat } \\
\text { check sheet } \\
\text { untuk } \\
\text { memastikan } \\
\text { pengisian oil } \\
\text { lubrication } \\
\text { terkontrol. }\end{array}$ & $\begin{array}{l}\text { Area } \\
\text { curing } \\
\text { tire } \\
\text { BTC. }\end{array}$ & $\begin{array}{l}P E- \\
\text { daily } \\
\text { BCHI. }\end{array}$ & $\begin{array}{l}10-15 \\
\text { Maret } \\
2018 .\end{array}$ & $\begin{array}{l}\text { Untuk memastikan } \\
\text { top up oil lubrication } \\
\text { dilakukan } \\
\text { berdasarkan jadwal } \\
\text { yang sudah ada dan } \\
\text { PIC yang } \\
\text { bertanggung jawab. }\end{array}$ \\
\hline 2 & Metode & $\begin{array}{l}\text { Oil } \\
\text { lubrication } \\
\text { terpasang } \\
\text { parsial pada } \\
\text { tiap lini } \\
\text { mesin. }\end{array}$ & $\begin{array}{l}\text { Membuat } \\
\text { sistem } \\
\text { central top } \\
\text { up oil } \\
\text { lubrication. }\end{array}$ & $\begin{array}{l}\text { Area } \\
\text { curing } \\
\text { tire } \\
\text { BTC. }\end{array}$ & $\begin{array}{l}P E- \\
\text { daily } \\
\text { BCHI. }\end{array}$ & $\begin{array}{l}10-29 \\
\text { Maret } \\
2018 .\end{array}$ & $\begin{array}{l}\text { Untuk } \\
\text { memungkinkan top } \\
\text { up oil lubrication } \\
\text { untuk semua lini } \\
\text { mesin dilakukan } \\
\text { pada satu lokasi } \\
\text { yang terpusat. }\end{array}$ \\
\hline 3 & Manusia & $\begin{array}{l}\text { Tidak peduli } \\
\text { terhadap } \\
\text { dampak } \\
\text { ketidak } \\
\text { konsistenan } \\
\text { dalam } \\
\text { melakukan } \\
\text { top up oil } \\
\text { lubrication. }\end{array}$ & $\begin{array}{l}\text { Memberikan } \\
\text { training } \\
\text { tentang } \\
\text { kesadaran } \\
\text { berkualitas. }\end{array}$ & $\begin{array}{l}\text { Area } \\
\text { curing } \\
\text { tire } \\
\text { BTC. }\end{array}$ & $\begin{array}{l}P E- \\
\text { daily } \\
\text { BCHI. }\end{array}$ & $\begin{array}{l}12-13 \\
\text { April } \\
2018 .\end{array}$ & $\begin{array}{l}\text { Menanamkan } \\
\text { kesadaran kepada } \\
\text { karyawan tentang } \\
\text { pentingnya } \\
\text { melakukan top up oil } \\
\text { lubrication pada } \\
\text { pneumatik. }\end{array}$ \\
\hline
\end{tabular}


Untuk melihat efektivitas proses perbaikan, diambil data produk green tyre bulan Mei 2018. Produk green tyre bulan Mei 2018 sebesar 330.060 buah dan jumlah cacat produk sebesar 4.699 buah. Evaluasi dilakukan dengan membandingkan jenis cacat green tyre bulan Februari dengan bulan Mei 2018 pada Table 4 dan membandingkan klasifikasi faktor penyebab cacat under cure bulan Februari dengan bulan Mei 2018 pada Tabel 5 sebagai berikut:

a. Analisis dan proses perbaikan kualitas dilakukan pada jenis cacat under cure yang disebabkan oleh problem pneumatik, hal ini karena under cure merupakan cacat dominan di antara keenam jenis cacat yang lain dan problem pneumatik merupakan penyumbang cacat paling dominan diantara kelima faktor penyebab cacat under cure.

b. Terjadi penurunan jumlah cacat produk green tyre sebesar $10,5 \%$ yaitu 5.250 pada Februari 2018 menjadi 4.699 pada Mei 2018 (Tabel 4).

c. Penurunan jumlah cacat terbesar adalah jenis cacat under cure sebesar $24,1 \%$ yaitu 2.088 pada Februari 2018 menjadi 1.585 pada Mei 2018 (Tabel 4).

d. Jenis cacat under cure karena problem pneumatik mengalami penurunan yang paling besar yaitu 48\% dari 891 pada Februari 2018 menjadi 463 pada Mei 2018 (Tabel 5).

Tabel 4. Perbandingan jenis cacat green tyre tahun 2018

\begin{tabular}{clcc}
\hline No & Jenis Cacat & Februari & Mei \\
\hline 1 & Open Mold & 791 & 782 \\
2 & Bead Crack & 407 & 411 \\
3 & Inner Pass & 779 & 760 \\
4 & Blond Tread & 828 & 800 \\
5 & Nero Bead & 357 & 361 \\
6 & Under Cure & 2088 & 1.585 \\
\hline & Jumlah & 5250 & 4.699 \\
\hline
\end{tabular}

Tabel 5. Perbandingan Faktor penyebab cacat under cure tahun 2018

\begin{tabular}{clcc}
\hline No & \multicolumn{1}{c}{ Penyebab } & Februari & Mei \\
\hline 1 & Pneumatic Problem & 891 & 463 \\
2 & Bladder Problem & 313 & 300 \\
3 & Topring Problem & 550 & 506 \\
4 & Overload & 167 & 168 \\
5 & Oil Pump Drop & 167 & 148 \\
\hline & Jumlah & 2088 & 1585 \\
\hline
\end{tabular}

Untuk menjaga hasil yang sudah dicapai maka dilakukan standarisasi yang meliputi:

a Menambahkan formulir check sheet pada prosedur top up oil lubrication.

Check sheet dibuat untuk memastikan Pengisian oil lubrication terkontrol. Dalam check sheet tercantum waktu top up, PIC serta verifikasi dari atasan.

b Membuat sistem central topup oil lubrication . Dengan sistem central top up oil lubrication memungkinkan top up oil lubrication untuk semua lini mesin dapat dilakukan pada satu lokasi yang terpusat.

c Memberikan training tentang kesadaran berkualitas.

Setelah infrastruktur dibangun (check sheet dan central top up oil lubrication) perlu ditanamkan kesadaran kepada karyawan tentang pentingnya melakukan top up oil lubrication pada pneumatic sehingga mereka menyadari betapa pentingnya melakukan top up oli secara baik dan teratur.

\section{KESIMPULAN}

Berdasarkan analisis data yang telah dilakukan diperoleh hasil bahwa faktor penyebab terbesar cacat green tyre disebabkan under cure. Pneumatic problem merupakan penyebab dominan terjadinya under cure. Pneumatic problem ini disebabkan oleh manusia yang tidak konsisten dalam melakukan top up oil lubrication, banyaknya lini mesin curing maka akan memerlukan waktu yang lama dalam melakukan top up oil lubrication dan Solenoid dan piston macet. Dari hasil perbaikan yang telah dilakukan diperoleh penurunan pneumatic problem sebesar 48\% dari 891 pieces di bulan Februari menjadi 463 pieces di bulan Mei. Cacat produk green tyre yang disebabkan under cure mengalami penurunan dari 2088 pieces menjadi 1585 pieces. Penelitian ini dapat dilanjutkan pada improvement untuk menyelesaikan masalah pada Topring Problem.

\section{DAFTAR PUSTAKA}

Bakhtiar, S., Tahir, S., \& Hasni, R. A. (2013). Analisa pengendalian kualitas dengan menggunakan metode statistical quality control (SQC). Industrial Engineering Journal, 2(1), 29-36.

Chandradevi, A., \& Puspitasari, N. B. (2016). Analisa Pengendalian Kualitas Produksi Botol X 500 Ml Pada PT. Berlina, Tbk Dengan Menggunakan Metode New Seven Tools. Industrial Engineering Online Journal, 5(4), 1-9. 
Girish, B. (2013). 7 Advanced QC Tools. Chennai : D L Shah Trust Publication.

Matondang, T. P., \& Ulkhaq, M. M. (2018). Aplikasi Seven Tools untuk Mengurangi Cacat Produk White Body pada Mesin Roller. Jurnal Sistem Dan Manajemen Industri, 2(2), 59-66.

Muhammad, S. (2015). Quality improvement of fan manufacturing industry by using basic seven tools of quality: A case study. International Journal of Engineering Research and Applications, 5(4), 30-35.

Neyestani, B. (2017). Seven Basic Tools of Quality Control: An Appropriate Tools for Solving Quality Problems in the Organizations.

Safrudin, Y. N., \& Sari, D. P. (2016). Analisis Penyebab Ketidaksesuaian Produk Adiprima pada PT. Adps Menggunakan Metode Seven Tools. Industrial Engineering Online Journal, 5(1).

Tague, N. R. (2005). The quality toolbox (Vol. 600). ASQ Quality Press Milwaukee, WI. 